\section{Por que parte da especialidade está sendo relegada a segundo plano dentro do diagnóstico por imagem?}

Why has part of the specialty been relegated to the backstage in the field of imaging diagnosis?

\section{Antonio Carlos Pires Carvalho}

Professor Associado do Departamento de Radiologia, Coordenador Adjunto do Programa de Pós-graduação em Medicina (Radiologia) da Universidade Federal do Rio de Janeiro (UFRJ), Rio de Janeiro, RJ, Brasil. E-mail: acpcrj@ hucff.ufrj.br

\section{Sr. Editor,}

Os radiologistas formados até meados dos anos 80 quase só tiveram oportunidade de aprender a velha, centenária, e hoje em dia relegada a um segundo plano, radiologia convencional, pois a maioria de nossos hospitais ligados ao ensino, com residência médica, não dispunha de ultrassonografia (US), outro método que começa a conhecer o limbo da preferência dos novos. Alguns dos "veteranos" enveredaram por esta seara, conseguiram aprender US, que usaram por muitos anos no dia-a-dia do seu trabalho. Outros enveredaram pelas trilhas da tomografia computadorizada (TC) e ressonância magnética (RM), por gosto pessoal e vontade de seguir tecnologia. Outros optaram por parar onde estavam.

Observa-se, em meio a estagiários, médicos residentes, mestrandos e doutorandos um "quase descaso" tanto em relação à radiologia convencional quanto à US. A TC e a RM, em contrapartida, atraem os olhares e gostos dos mais novos. Curiosamente, toda a base do diagnóstico por imagem é a velha radiologia convencional. A partir dela é que se aprende a interpretar, pensar, variar e sugerir outras coisas. Tenta-se descobrir alguma razão além do simples retorno financeiro para isso, pois já se foi o tempo em que quem fazia RM ganhava quanto queria. Creio que se pode afirmar que o papel se inverteu. Com tanta gente nova só se preocupando em aprender RM e TC, quem sabe fazer e dar laudo com qualidade nos "velhos exames" voltará em breve a ter valor no "mercado"?

Então, preocupado com essa tendência, em especial no quase manifesto desgosto que alguns residentes mostram por perder tempo aprendendo radiologia convencional e US, fizemos um levantamento na revista Radiologia Brasileira (RB), para ver o que ainda é publicado sobre estas "subespecialidades" quase abandonadas. O levantamento foi feito procurando por publicações dos últimos dez anos, que seriam um bom referencial. Com a palavra ultra-sonografia, escrita à moda antiga, com hífen, encontram-se 77 artigos. Passando então para a grafia atual, ultrassonografia com duplo s, foram publicados na RB 63 artigos desde 2009.

Para comparar, busca-se um salto internacional. Quem sabe "abaixo do equador" somos obsoletos e no primeiro mundo não se faz mais esta coisa. No PubMed, digitando ultrasound, aparecem mais de 387 mil referências, sendo mais de 98 mil nos últimos cinco anos e quase $180 \mathrm{mil} \mathrm{em} \mathrm{dez} \mathrm{anos.} \mathrm{Digi-}$ tando $x$-ray e limitando a procura a dez anos, alguém arrisca um número? Mais de 350 mil artigos. Voltando à RB e digitando radiografia, surgem 55 artigos. Fazendo a procura com "radiografia OU convencional", aparecem 83 referências.

Diante dessa quantidade de referências, quais seriam os temas destes artigos? Fica-se gratificado, muito satisfeito, por ver que trabalhos muito interessantes ainda são feitos e publicados a partir desses métodos. Alguns estão aqui listados: gossipiboma abdominal ${ }^{(\mathbf{1})}$, quatro belos relatos de caso $^{(2-5)}$,

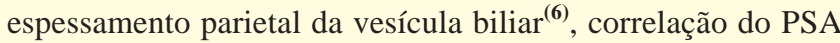
com câncer de próstata ${ }^{(7)}$, estudo dos ventrículos cerebrais ${ }^{(8)}$, US na classificação BI-RADS ${ }^{(\mathbf{9})}$, sangramento uterino anormal $^{(10)}$, complexo médio-intimal em aterosclerose ${ }^{(11)}$, comparação de US e RM no fluxo portal ${ }^{(\mathbf{1 2})}$, endoleaks no tratamento endovascular de aneurismas aórticos ${ }^{(\mathbf{1 3})}$, anormalidades do primeiro trimestre da gravidez ${ }^{(\mathbf{1 4})}$, alterações radiográficas pulmonares no tratamento da paracoccidioidomicose ${ }^{(15)}$, neurofibromatose $^{(\mathbf{1 6})}$, estudo da coluna cervical após tração ${ }^{(17)}$, e finalizando, três artigos abordando física médica ${ }^{(\mathbf{1 8}-20)}$.

Certamente outros leitores terão outras preferências.

Cabe então perguntar: será que abandonar estas áreas do conhecimento radiológico tem alguma lógica, é sinal de bom senso? Ainda que seja por pensar apenas no lado financeiro da profissão, saber algo mais que TC e RM pode ser muito bom. Nem que seja para permanecer diferenciado num mercado de trabalho cada vez mais exigente e, talvez, pasteurizado. Creio que os residentes destes "tempos modernos" (citando o genial Chaplin) devem pensar nisso. Nem há necessidade de criar um diferencial, basta não perdê-lo...

\section{REFERÊNCIAS}

1. Chagas Neto FA, Agnollitto PM, Mauad FM, et al. Avaliação por imagem dos gossipibomas abdominais. Radiol Bras. 2012;45:53-8.

2. Mizerkowski MD, Spolidoro JVN, Epifanio M, et al. Divertículo de Mecke ao Doppler em cores: relato de dois casos. Radiol Bras. 2011;44:268-70.

3. Rios LTM, Oliveira RVB, Martins MG, et al. Lipoma espinhal associado a seio dérmico congênito: relato de caso. Radiol Bras. 2011;44:265-7.

4. Braga FNHF, Braga MV, Andrade Neto F. Doença de Paget com acometimento sacral: relato de caso. Radiol Bras. 2010;43:339-42.

5. Baldisserotto M, Fiori H, Fiori R, et al. Neonato com ascite urinária e ruptura de cálice renal secundárias a válvula de uretra posterior: diagnóstico ultrassonográfico. Radiol Bras. 2011;44:68-70.

6. Barbosa ABR, Souza LRMF, Pereira RS, et al. Espessamento parietal da vesícula biliar no exame ultrassonográfico: como interpretar? Radiol Bras. 2011;44:381-7

7. Castro HAS, Iared W, Shigueoka DC, et al. Contribuição da densidade do PSA para predizer o câncer da próstata em pacientes com valores de PSA entre 2,6 e 10,0 ng/ml. Radiol Bras. 2011;44:205-9.

8. Garcia RF, Lederman HM, Brandão J. Estudo dos ventrículos cerebrais por ultrassonografia, na criança normal, nascida a termo, de 1 a 6 meses. Radiol Bras. 2011;44:349-54.

9. Calas MJG, Alvarenga AV, Gutfilen B, et al. Avaliação de parâmetros morfométricos calculados a partir do contorno de lesões de mama em ultrassonogra- 
fias na distinção das categorias do sistema BI-RADS. Radiol Bras. 2011;44: 289-96.

10. Feitosa IMSD, Feitosa HN, Carvalho FHC, et al. Comparação entre ultrassonografia transvaginal e histerossonografia na avaliação de pacientes com sangramento uterino anormal. Radiol Bras. 2011;44:156-62.

11. Soares CM, Koch HA, Montenegro CAB, et al. Dilatação fluxo-mediada da artéria braquial e complexo médio-intimal das artérias carótida e braquial: avaliação de indivíduos com e sem fatores de risco para aterosclerose. Radiol Bras. 2010;43:389-93.

12. Leão ARS, Sales DM, Santos JEM, et al. Avaliação do volume de fluxo portal em pacientes esquistossomóticos: estudo comparativo entre ressonância magnética e ultrassom Doppler. Radiol Bras. 2010;43:355-61.

13. Chagas Neto FA, Barreto ARF, Reis HF, et al. A importância do diagnóstico por imagem na classificação dos endoleaks como complicação do tratamento endovascular de aneurismas aórticos. Radiol Bras. 2010;43:289-94.

14. Rios LTM, Oliveira RVB, Martins MG, et al. Anormalidades do primeiro trimestre da gravidez: ensaio iconográfico. Radiol Bras. 2010;43:125-32.
15. Moraes CS, Queiroz-Telles F, Marchiori E, et al. Análise das alterações radiográficas pulmonares durante a terapêutica da paracoccidioidomicose. Radiol Bras. 2011;44:20-8.

16. Muniz MP, Souza AS, Criado DAB, et al. Neurofibromatose tipo 1: aspectos radiológicos do tórax. Radiol Bras. 2010;43:167-70.

17. Souza RB, Lavado EL, Medola FO, et al. Análise radiográfica da coluna cervical em indivíduos assintomáticos submetidos a tração manual. Radiol Bras. 2008;41:245-9.

18. Soares FAP, Pereira AG, Flôr RC. Utilização de vestimentas de proteção radiológica para redução de dose absorvida: uma revisão integrativa da literatura. Radiol Bras. 2011;44:97-103.

19. Luz RM, Hoff G. Estudo comparativo da qualidade da imagem e do kerma, de entrada e de saída, em simulador de tórax utilizando sistemas analógico e digitalizado CR de aquisição de imagens. Radiol Bras. 2010;43:39-45.

20. Parizoti A, Ghilardi Netto T. Estudo de otimização de imagens em fluoroscopia intervencionista. Radiol Bras. 2009;42:375-8. 